\title{
Measures of self-efficacy and norms for low-fat milk consumption are reliable and related to beverage consumption among 5 th graders at school lunch
}

\author{
Victoria J Thompson ${ }^{1, *}$, Christine Bachman ${ }^{2}$, Kathy Watson ${ }^{3}$, Tom Baranowski ${ }^{3}$ and \\ Karen W Cullen ${ }^{3}$ \\ 'The University of Texas, M.D. Anderson Cancer Center, Unit 182, 1515 Holcombe Boulevard, Houston, \\ TX 77030, USA: ${ }^{2}$ University of Houston, - Downtown, Houston, TX, USA: ${ }^{3}$ Baylor College of Medicine, \\ USDA/ARS Children's Nutrition Research Center, Houston, TX, USA
}

Submitted 12 December 2006: Accepted 4 May 2007: First published online 1 August 2007

\begin{abstract}
Objective: To determine the reliability and validity of scales measuring low-fat milk consumption self-efficacy and norms during school lunch among a cohort of 5 th graders.

Design: Two hundred and seventy-five students completed lunch food records and a psychosocial questionnaire measuring self-efficacy and norms for school lunch low-fat milk consumption during the fall and spring semesters of the 1998-1999 academic year. Test-retest reliability was assessed in participants who also completed the questionnaire in the spring semester $(n=262)$. Principal component analyses identified and confirmatory factor analyses confirmed latent variables. Bivariate correlations measured construct validity.

Setting: Houston-area middle school.

Subjects: Fifth graders $(n=275)$ from one middle school in southeast Texas.

Results: Two scales measuring psychosocial influences of low-fat milk consumption were identified and proved reliable in this population: milk self-efficacy and milk norms. Milk self-efficacy and norms were positively correlated with milk consumption and negatively correlated with consumption of sweetened beverages. Conclusions: These questionnaires can be used in similar interventions to measure the impact of self-efficacy and norms for drinking low-fat milk during school lunch.
\end{abstract}

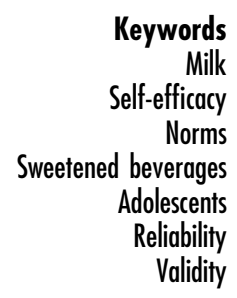

Milk is a major dietary source of calcium in the USA and its consumption throughout childhood and adolescence is important to support growth and the development of optimal bone mass ${ }^{1-3}$. Milk consumption has been associated with weight management ${ }^{4,5}$ and inversely associated with the consumption of sweetened beverages ${ }^{6}$. Children with dental caries had lower intakes of milk as toddlers and young children than their counterparts without caries ${ }^{7}$. Inadequate milk consumption was related to inadequate intakes of vitamin A, folate, calcium, phosphorus and magnesium ${ }^{8}$.

Despite the need for milk and calcium in development, milk intake declines from childhood to adolescence ${ }^{9-12}$. Despite one serving of milk included in the National School Lunch Program (NSLP) meal, adolescent milk consumption declines even in the school environment ${ }^{12,13}$. This decline may be partly attributed to the competing alternatives available in à la carte bars and vending machines that students encounter in middle school $^{12,13}$.
Understanding the salient motivators and barriers to milk consumption among children and adolescents informs intervention design. Previous research has identified factors related to calcium and dairy consumption. These include age, gender, socio-economic status, body weight, taste preferences ${ }^{14}$, lactose intolerance ${ }^{15}$, soft drink intake ${ }^{16}$ and self-efficacy ${ }^{14}$. One's sense of selfefficacy (or confidence) may play a role in both drinking milk and overcoming barriers to drinking milk ${ }^{17}$. Selfefficacy motivates effort and persistence ${ }^{18,19}$. In addition, subjective norms - i.e. one's judgement about whether or not others will approve of one's behaviour - and social norms - i.e. one's beliefs regarding the expected level of behaviour in a particular social $\operatorname{context}^{20}-$ may also influence milk consumption.

There has been some concern about the low predictiveness of dietary intake by psychosocial variables among children, since children do not always control the selection of what they eat ${ }^{21}$. In school, however, children exercise control over their beverage selection, particularly 
when students are transitioning from NSLP-only meals in elementary school to middle schools where snack bars are available. In the present study students were introduced to NSLP alternatives in the first semester of the 5th grade. The present observational study examined the reliability and validity of new scales of self-efficacy and norms regarding low-fat milk consumption during school lunch among 5th grade youth.

\section{Methods}

This observational study was approved by the Institutional Review Board of the University of Texas M.D. Anderson Cancer Center. It was part of a larger study, the objective of which was to examine the influence of school snack bars on fruit and vegetable and beverage intakes of middle-school students ${ }^{12,13,22}$.

\section{Population}

All 5 th grade students $(n=422)$ from one 5 th and 6 th grade middle school in southeast Texas were invited to participate. Written parental consent and youth assent were obtained. Students attending this middle school had access to a snack bar/à la carte line and the NSLP meal. No school store was available. In 1998-1999, the district included 18\% African-American, 24\% Mexican-American, 57\% EuroAmerican and 1\% Asian/Other students. Approximately $24 \%$ of the students within the district were eligible for free/ reduced-price meals. Study participants were $42 \%$ male; 13\% were African-Americans, 27\% Mexican-Americans, 49\% Euro-Americans and 11\% Asian/Other. Data were not collected on NSLP eligibility of participants.

\section{Instruments and data collection}

\section{Food records}

Students completed lunch food records for five consecutive days during the fall and spring semesters, for a total of 10 days of food records for the school year. These records were completed in the cafeteria or in the classroom after each lunch period, thereby minimising error of report due to time-related memory ${ }^{23}$. Trained data collectors instructed students on how to properly and accurately complete the food records. Students listed each food item consumed during school lunch on separate blank lines, and indicated the number of servings consumed and the source (NSLP, snack bar, home). Immediately after students completed the food records and before the lunch period was over, data collectors checked the food records for missing data and ensured that all food items were described properly. Dietary data collection via food records has been shown to be valid ${ }^{23}$. In accordance with the serving sizes (i.e. one serving $=8 \mathrm{oz}$ milk; one serving $=12 \mathrm{oz}$ sweetened beverages) of the 1998 Food Guide Pyramid, the food records were coded for milk (high-fat, i.e. whole flavoured or plain milk; or low-fat, i.e. $2 \%$ fat or less in flavoured or plain milk) and sweetened beverages (i.e. water-based beverages that contain sugar) by trained dietitians.

\section{Psychosocial questionnaire}

On the first day of each spring and fall data collection week and immediately following lunch, consented students also completed an 11-item questionnaire which asked questions related to influences on low-fat milk intake during school lunch. Specifically, the items were chosen to reflect self-efficacy for selecting and drinking milk during school lunch. The norms items reflect peer influence on drinking milk during school lunch. The overall Flesch/Kincaid readability score was at a 5.0 grade level. Self-efficacy was measured using a three-point response scale. Norms were measured with four-point scale items (Table 1).

\section{Data analyses}

\section{Data preparation}

Analyses were conducted on data from the fall 1998 ( $n=275)$ and spring $1999(n=262)$ semesters. Survey items were normalised to minimise the effects of using three- and four-category response scales. Items within scales were averaged for fall and spring, separately. All variables were normally distributed. Less than $5 \%$ of the data were missing and no obvious patterns existed among missing data.

Servings of milk and sweetened beverages (i.e. waterbased beverages that contain sugar) were summed for each day and the mean across the five days of collection was calculated for each child at each of the two time intervals.

\section{Reliability}

The psychosocial questionnaire from fall $1998(n=275)$ was subject to principal component analysis (PCA) with Varimax rotation using SPSS 11.0. The number of factors to be retained was determined from the scree plot, factor loadings and the interpretability of resulting factors. Only items loading on a factor with a minimum factor loading of 0.40 were retained. Ten of the 11 items loaded on one of two factors: milk norms and milk self-efficacy (Table 1). Internal consistency and test-retest reliability of the two factors were analysed using Cronbach's $\alpha$ and Pearson correlation, respectively. To assess whether the factor solutions were stable, factor patterns were examined using both measurement periods of the study (i.e. 1998 and 1999).

To measure the stability of beverage consumption, the intra-class correlation (ICC) of reliability was calculated for each of the dietary intake variables (i.e. sweetened beverages, total milk, high-fat milk, low-fat milk) for a single day and for the average over the five days of intake 
Table 1 Scale indicators and factor loadings for the two-factor solution using principal component analysis (PCA) and confirmatory factor analyses (CFA)

\begin{tabular}{|c|c|c|}
\hline & $\begin{array}{l}\text { PCA factor loadings } \\
\quad(n=275)\end{array}$ & $\begin{array}{l}\text { CFA loadings } \\
\quad(n=262)\end{array}$ \\
\hline $\begin{array}{l}\text { Leading statements for self-efficacy scales: } \\
{ }^{\star} \text { At school, how sure are you that you can... } \\
{ }^{*} \text { When you eat at the school snack bar, how sure are you that you can... }\end{array}$ & & \\
\hline \multicolumn{3}{|l|}{ Questions from milk self-efficacy scalet } \\
\hline *... drink low-fat milk once or twice a week? & 0.78 & 0.77 \\
\hline${ }^{\star} \ldots$.. drink low-fat milk for every lunch? & 0.76 & 0.77 \\
\hline *... drink low-fat milk even if your friends are not drinking low-fat milk? & 0.81 & 0.80 \\
\hline $\begin{array}{l}\text { *...finish drinking low-fat milk, even if your friend says something bad about low-fat } \\
\text { milk? }\end{array}$ & 0.78 & 0.79 \\
\hline **...buy low-fat milk once or twice a week? & 0.82 & 0.87 \\
\hline **... buy low-fat milk at every lunch? & 0.80 & 0.82 \\
\hline${ }^{\star *} \ldots$ buy low-fat milk even if your friends are not? & 0.83 & 0.85 \\
\hline \multicolumn{3}{|l|}{ Questions from milk norms scaleł } \\
\hline My friends drink low-fat milk at school lunch when I am with them§ & 0.78 & 0.87 \\
\hline Most kids drink low-fat milk at school lunch $\S$ & 0.77 & 0.78 \\
\hline \multirow[t]{2}{*}{ How much do your friends encourage you to drink low-fat milk at school lunch? } & 0.55 & 0.59 \\
\hline & Milk self-efficacy (7 items) & Milk norms (3 items) \\
\hline \multicolumn{3}{|l|}{ PCA factor structure and scale means } \\
\hline Eigenvalue & 5.33 & 1.47 \\
\hline$\%$ Variance explained & 48.49 & 13.36 \\
\hline Cronbach's $\alpha \|^{\prime}$ & 0.93 & 0.65 \\
\hline Pearson test-retest & 0.75 & 0.54 \\
\hline Scale mean (standard deviation) & $0.89(0.67)$ & $0.83(0.60)$ \\
\hline
\end{tabular}

† Responses for self-efficacy scale: ‘I cannot’ =0; ‘a little sure I can’ = 1; 'very sure I can’ = 2 .

$¥$ The following item did not load on either scale: 'Most kids my age think that drinking low-fat milk at school is...' (responses: 'a very good thing', 'a good thing', 'they don't care', 'I don't know').

$\$$ Responses for norms scale: 'never' $=0$; 'sometimes' $=1$; 'often' $=2$; 'always' $=3$.

- Responses for norms scale: 'they tell me not to' $=0$; 'not at all' = 1; 'a little' =2; 'a lot' $=3$.

$\|$ Cronbach's $\alpha$ for CFA (spring 1999): milk self-efficacy $=0.92$; milk norms $=0.60$.

during the spring and the fall semesters, giving a total of two measures for each intake variable.

\section{Measurement model}

The 1999 dataset was used for confirmatory factor analyses (CFA) (i.e. to test the reliability of the 1998 PCA data) using AMOS 5.0 24. CFA were conducted using the measurement model to determine how well the indicators loaded on the appropriate latent variable using the normalised 1999 dataset $^{25-29}$. Interpretation of the association between the measured and latent variables, and the internal consistency of the scales, were used to determine inclusion of variables in the measurement models.

\section{Construct validity}

Using the fall 1998 data, bivariate Pearson correlations were performed to measure construct validity between the psychosocial factors and the consumption of sweetened beverages and low-fat milk.

\section{Results}

\section{Consumption}

Average student consumption of total milk and sweetened beverages at school lunch was less than half a serving per day (Table 2). Most milk consumed (80\%) was low-fat. Using a single measure, the ICC reliabilities were low (range 0.46-0.57); however, when calculating ICC as an average across the five days of intake during each semester, the values ranged from 0.78 to 0.84 (Table 2).

\section{Reliability}

Two factors were obtained. Internal reliabilities for the self-efficacy and norms scales were consistent for both datasets (i.e. 1998 and 1999) (Table 1). Test-retest for the self-efficacy and norms scales was 0.75 and 0.54, respectively (Table 1 ).

Using the 1999 normalised data, CFA confirmed a twofactor model of influences on milk consumption. The fit of the 10-item model was adequate and yielded $\chi_{\mathrm{df}(28)}^{2}=63.3, \quad P<0.001$, comparative fit index $=0.98$, root-mean-square error of approximation $=0.07$. Three items loaded on norms, range 0.44 to 0.56 . Seven items loaded on self-efficacy, range 0.66 to 0.86 .

\section{Construct validity}

Milk self-efficacy was negatively correlated to the consumption of sweetened beverages $(r=-0.34, P<0.01)$ and positively correlated to total milk $(r=0.35, P<0.01)$, 
Table 2 Mean (standard deviation) and intra-class correlation (ICC) for consumption of milk and sweetened beverages at school lunch

\begin{tabular}{|c|c|c|c|c|c|c|}
\hline & & & \multicolumn{4}{|c|}{$I^{\prime C C}{ }^{*}$} \\
\hline & \multicolumn{2}{|c|}{ Consumption at lunch (daily servings) } & \multicolumn{2}{|c|}{ Fall 1998} & \multicolumn{2}{|c|}{ Spring 1999} \\
\hline & Fall 1998 & Spring 1999 & Single & Average & Single & Average \\
\hline Total milk & $0.39(0.38)$ & $0.35(0.39)$ & 0.49 & 0.83 & 0.51 & 0.80 \\
\hline High-fat milk & $0.08(0.20)$ & $0.06(0.17)$ & 0.53 & 0.84 & 0.46 & 0.78 \\
\hline Low-fat milk & $0.31(0.35)$ & $0.30(0.37)$ & 0.47 & 0.81 & 0.57 & 0.83 \\
\hline Sweetened beverages & $0.48(0.40)$ & $0.48(0.40)$ & 0.49 & 0.81 & 0.53 & 0.80 \\
\hline
\end{tabular}

${ }^{*} \mathrm{ICC}$ single and average values are the reliabilities associated with using a single measure and the average measure across the five days of assessment, respectively.

low-fat milk $(r=0.30, \quad P<0.01)$ and high-fat milk ( $r=0.15, P<0.05)$ consumption. The milk norms scale was also negatively correlated with sweetened beverage consumption $(r=-0.19, P<0.01)$ and positively correlated to total milk $(r=0.20, P<0.01)$ and low-fat milk consumption $(r=0.18, P<0.01)$.

\section{Discussion}

This study examined the reliability and validity of questionnaires measuring school lunch self-efficacy and norms for low-fat milk consumption among 5 th graders. CFA confirmed that the two factors emerging from the 1998 PCA loaded on the respective latent variables using the spring 1999 data. Since $\alpha$ is primarily a function of the number of items included in a scale, a higher value for internal reliability was expected for the self-efficacy scale than for the norms scale.

Although the reliability of a single day's beverage intake was low, the reliability using the average across the five days was acceptable, indicating an acceptable level of stability in beverage consumption among the students. Because test-retest reliability values have declined within a few weeks in children ${ }^{30}$, the adequate values herein are somewhat surprising as the questionnaires were administered several months apart. While similar values have been noted in pre-school children ${ }^{31}$, the pre-school values represent food preferences which are relatively stable, even in children ${ }^{32}$. We found no test-retest values that examined school lunch self-efficacy and norms among students as they transitioned from NSLP-only school lunch to school lunch with NSLP-competing alternatives. Hence, the test-retest values reported in this study are of particular interest because these middleschool students were faced with making beverage choices each day. Equally noteworthy is that less than $5 \%$ of meals were brought from home ${ }^{13}$, suggesting that students self-selected low-fat milk from the school cafeteria although whole milk was also available.

A more general understanding of the psychosocial factors influencing milk consumption among children and adolescents is derived from previous studies which measured influences and intake using food-frequency questionnaires $^{14,33}$. No study, however, was found that specifically examined consumption of low-fat milk during lunch at school, particularly when student norms may be changing to reflect a more competitive cafeteria environment. This more specific assessment provides insight into school-based intervention designs.

Self-efficacy assessed students' confidence that they could consume low-fat milk during school lunch. Not surprisingly, students' self-efficacy for low-fat milk consumption was negatively correlated to sweetened beverage consumption and positively correlated to total, high-fat and low-fat milk consumption. These findings underscore those of Larson et al. ${ }^{14}$ in which students' selfefficacy to make healthy choices was related to dairy and calcium intakes. While the questionnaire referred to lowfat milk, perhaps students who selected whole milk ignored the distinction and completed the questions indicating their self-efficacy to choose milk.

Consistent with previous work $^{33}$, student norms regarding low-fat milk consumption during school lunch also predicted healthier eating habits. The results indicate that specific norms such as modelling, subjective norms and peer encouragement are positively related to healthy eating habits, particularly total milk consumption, during school lunch among 5 th graders. The correlation between milk consumption and the three-item norms scale mirrors previous $^{33}$ findings that behavioural modelling, perceptions of others' recommendations and use of milk influence milk consumption. In the present investigation these norms items were not predictive of high-fat milk consumption, possibly because high-fat milk consumption was so low, or suggesting that high-fat milk consumption at school is not influenced by social pressure or behavioural expectations as is low-fat milk consumption.

Several limitations should be noted. All data were from self-report, with potential errors from memory and estimation of portion sizes. The participants were from one school in southeast Texas, potentially limiting generalisability. Further, self-assessment of psychosocial influences, particularly norms, at this age and during this critical time of transition may be rather tenuous. Testing whether preferences mediated any of these relations may further elucidate the psychosocial influences. Future research should test these questionnaires with 
middle-school students in other areas of the country. Whether these constructs are important for youth in high school is also an important question for further study, given that sweetened beverage intake increases throughout the teen years ${ }^{10}$.

Of middle-school students who have to make beverage choices each day at school, to our knowledge this is the first study to simultaneously measure self-efficacy and norms with beverage intake. The potential roles for lowfat milk self-efficacy and norms for consuming low-fat milk are important in designing more effective interventions to increase low-fat milk and decrease sweetened beverage consumption. For example, schools could be encouraged to sponsor tasting of various types of low-fat milks, and provide posters and point-of-service advertisements to promote the low-fat choices. Students would have the opportunity to observe classmates consuming the low-fat milk. This would potentially reset the norm for low-fat milk consumption in middle schools. These questionnaires are available for use to measure the impact of these interventions on self-efficacy and norms.

\section{Acknowledgements}

Sources of funding: This work is a publication of the US Department of Agriculture (USDA)/Agricultural Research Service (ARS) Children's Nutrition Research Center, Department of Pediatrics, Baylor College of Medicine and Texas Children's Hospital, Houston, Texas. This project has been funded in part by federal funds from the USDA/ ARS under Cooperative Agreement No. 58-6250-6001. The contents of this publication do not necessarily reflect the views or policies of the USDA, nor does mention of trade names, commercial products, or organisations imply endorsement by the US Government. This work was also supported by grants CA88511 and CA88511-01S1 from the National Cancer Institute.

Conflict of interest declaration: There are no conflicts of interest.

Authorship responsibilities: V.J.T. conducted data analyses and wrote the manuscript. C.B. participated in data analyses, particularly SEM, as well as manuscript developments. T.B. contributed to data analyses and interpretation, K.W.C., the principal investigator, conceived the study hypothesis and authored the grant. All co-authors made substantial contributions to data analysis, data interpretation and the writing of the manuscript.

Acknowledgements: The authors wish to thank Drs Virginia Kennedy, Asha Kapadia and Jeanne Martin of the University of Texas Health Science Center at Houston for their editorial comments.

\section{References}

1 Black RE, Williams SM, Jones IE, Goulding A. Children who avoid drinking cow milk have low dietary calcium intakes and poor bone health. American Journal of Clinical Nutrition 2002; 76: 675-80.

2 Bonjour JP, Carrie AL, Ferrari S, Clavien H, Slosman D, Theintz G, et al. Calcium-enriched foods and bone mass growth in prepubertal girls: a randomized, double-blind, placebo-controlled trial. Journal of Clinical Investigation 1997; 99: 1287-94.

3 Volek JS, Gomez AL, Scheett TP, Sharman MJ, French DN, Rubin MR, et al. Increasing fluid milk favorably affects bone mineral density responses to resistance training in adolescent boys. Journal of the American Dietetic Association 2003; 103: 1353-6.

4 Zemel MB. Role of calcium and dairy products in energy partitioning and weight management. American Journal of Clinical Nutrition 2004; 79: 907S-12S.

5 Zemel MB, Miller SL. Dietary calcium and dairy modulation of adiposity and obesity risk. Nutrition Reviews 2004; 62: 125-31.

6 Blum JW, Jacobsen DJ, Donnelly JE. Beverage consumption patterns in elementary school aged children across a twoyear period. Journal of the American College of Nutrition 2005; 24: 93-8,

7 Marshall TA, Levy SM, Broffitt B, Warren JJ, EichenbergerGilmore JM, Burns TL, et al. Dental caries and beverage consumption in young children. Pediatrics 2003; 112: e184-91.

8 Bowman SA. Beverage choices of young females: changes and impact on nutrient intakes. Journal of the American Dietetic Association 2002; 102: 1234-9.

9 Nielsen SJ, Popkin BM. Changes in beverage intake between 1977 and 2001. American Journal of Preventive Medicine 2004; 27: 205-10.

10 Forshee RA, Storey ML. Total beverage consumption and beverage choices among children and adolescents. International Journal of Food Sciences and Nutrition 2003; 54: 297-307.

11 Rampersaud GC, Bailey LB, Kauwell GP. National survey beverage consumption data for children and adolescents indicate the need to encourage a shift toward more nutritive beverages. Journal of the American Dietetic Association 2003; 103: 97-100.

12 Cullen KW, Zakeri I. Fruits, vegetables, milk, and sweetened beverages consumption and access to a la carte/snack bar meals at school. American Journal of Public Health 2004; 94: 463-7.

13 Cullen KW, Eagan J, Baranowski T, Owens E, de Moor C. Effect of a la carte and snack bar foods at school on children's lunchtime intake of fruits and vegetables. Journal of the American Dietetic Association 2000; 100: 1482-6.

14 Larson NI, Story M, Wall M, Neumark-Sztainer D. Calcium and dairy intakes of adolescents are associated with their home environment, taste preferences, personal health beliefs, and meal patterns. Journal of the American Dietetic Association 2006; 106: 1816-24.

15 Auld G, Boushey C, Bock M, Bruhn C, Gabel K, Gustafson $\mathrm{D}$, et al. Perspectives on intake of calcium-rich foods among Asian, Hispanic, and white preadolescent and female adolescents. Journal of Nutrition Education and Behavior 2002; 34: 242-51.

16 Harnack L, Stang J, Story M. Soft drink consumption among US children and adolescents: nutritional consequences. Journal of the American Dietetic Association 1999; 99: 436-41.

17 Bandura A. Social Foundations of Thought and Action: A Social Cognitive Theory. Englewood Cliffs, NJ: Prentice-Hall, Inc., 1986.

18 Bandura A. Self-efficacy: toward a unifying theory of behavioral change. Psychological Review 1977; 84: 191-215. 
19 Garcia K, Mann T. From 'I wish to I will': social-cognitive predictors of behavioral intentions. Journal of Health Psychology 2003; 8: 347-60.

20 Ajzen I. Perceived behavioral control, self-efficacy, locus of control, and the Theory of Planned Behavior. Journal of Applied Social Psychology 2002; 32: 1-20.

21 Baranowski T, Cullen KW, Baranowski J. Psychosocial correlates of dietary intake: advancing dietary intervention. Annual Review of Nutrition 1999; 19: 17-40.

22 Thompson VJ, Bachman CM, Baranowski T, Cullen KW. Self-efficacy and norm measures for lunch fruit and vegetable consumption are reliable and valid among fifth grade students. Journal of Nutrition Education and Behavior 2007; 39: 2-7.

23 Domel SB, Baranowski T, Leonard SB, Davis H, Riley P, Baranowski J. Accuracy of fourth and fifth grade students' food diaries compared to school lunch observation. American Journal of Clinical Nutrition 1994; 54(Suppl.): 218S-20S.

24 Arbuckle J, Wothke W. AMOS 4 User's Reference Guide. Chicago, IL: Smallwaters Corp., 1999.

25 Hoyle RH, Panter AT. Writing about structural equation models. In: Hoyle RH, ed. Structural Equation Modeling: Concepts, Issues, and Applications. Thousand Oaks, CA: Sage Publications, Inc., 1995; 158-76.

26 Klem L. Structural equation modeling. In: Grimm LG, Yarnold PR, eds. Reading and Understanding More Multi- variate Statistics. Washington, DC: American Psychological Association, 2000; 227-60.

27 Carnines E, McIver J. Analyzing models with unobserved variables: analysis of covariance structures. In: Bohrnstedt GW, Borgatta EF, eds. Social Measurement: Current Issues. Beverly Hills, CA: Sage Publications, Inc., 1981; 65-15.

28 Bentler PM, Bonett DG. Significance tests and goodness of fit in the analysis of covariance structures. Psychological Bulletin 1980; 88: 588-606.

29 Browne MW, Cudeck R. Alternative ways of assessing model fit. In: Bollen KA, Long JS, eds. Testing Structural Equation Models. Thousand Oaks, CA: Sage Publications, Inc., 1993; 135-62.

30 Resnicow K, Davis-Hearn M, Smith M, Baranowski T, Lin S, Baranowski J, et al. Social-cognitive predictors of fruit and vegetable intake in children. Health Psychology 1997; 16: 272-6.

31 Jaramillo SJ, Yang SJ, Hughes SO, Fisher JO, Morales M, Nicklas TA. Interactive computerized fruit and vegetable preference measure for African-American and Hispanic preschoolers. Journal of Nutrition Education and Behavior 2006; 38: 352-8.

32 Skinner JD, Carruth BR, Wendy B, Ziegler PJ. Children's food preferences: a longitudinal analysis. Journal of the American Dietetic Association 2002; 102: 1638-47.

33 Barr SI. Associations of social and demographic variables with calcium intakes of high school students. Journal of the American Dietetic Association 1994; 94: 260-6. 